\title{
In-situ Cryo-TEM Investigations of Ice Crystallization from Supercooled Water and Interactions between Solid/Liquid Interface and Nanoparticles
}

\author{
Kaiping Tai, and Shen Dillon \\ Department of Materials Science and Engineering, University of Illinois Urbana-Champaign, Urbana, \\ IL 61801 USA
}

Water is the most common and valuable constituent in our lives. Water has a wide variety of solid-state (ice) polymorphs under diverse te mperature and pressure conditions. Water-ice phase form ation and transitions play crucially im portant roles in $\mathrm{m}$ any fundamental phenomena, from materials science to atmospheric science, and have attrac ted intensive research interest in the past decades [1-5]. However, many basic issues including the $\mathrm{m}$ echanisms of ice nucleation, solidificat ion, and $\mathrm{m}$ icrostructural evolution are still not w ell understood. At am bient pressure, water commonly crystallizes into a stable hexagonal structured phase and a $\mathrm{m}$ etastable cubic phase. These two ice phases have very sim ilar physical properties as well as form ation energies [6]. A variety of techniques have been applied to characterize ice crys tallization [7], but direct observation of the pr ocess at the nanoscale is s till of lacking. The present work develops a tem perature controlled cooling system for an enclosed environmental cell in the TEM. The apparatus com bines a cold finger, resistive heating, and a thermocouple-based temperature feedback system. The technique enables the in-situ characterization of ice crystallization with good tem poral $(\sim 100 \mathrm{~ms})$ and sp atial resolutions $(\sim 5 \mathrm{~nm})$. At low freezing rates, the ice crystallizes in the hexagonal phase growing with $<-1100>$ growth facets, as shown in Fig. 1 . This approach provides a variety of new opportunities to $i$ nvestigate the water-ice sy stem at the nanoscale and has relevance to a number of scientific and engineering disciplines.

\section{References:}

[1] C. Y. Ruan et al, Science, 304 (2004), p. 80.

[2] T. L. Malkin et al, Proc. Natl. Acad. Sci. USA, 109 (2012), p. 1041.

[3] W. F. Kuhs et al, Proc. Natl. Acad. Sci. USA, 109 (2012), p. 21259.

[4] S. Deville et al, Nature Mater. 8 (2009), p. 966.

5] S. S. L. Peppin et al, J. Fluid Mech. 554 (2006), p. 147.

[6] J. C. T. Kao et al, J. Fluid Mech. 625 (2009), p. 299.

[7] K. Kobayashi et al, Phys. Rev. Lett. 106 (2011), p. 206101.

[8] The authors acknowledge funding from the U.S. Department of Energy, Basic Energy Sciences (Contract No. DE-SC0006509). 


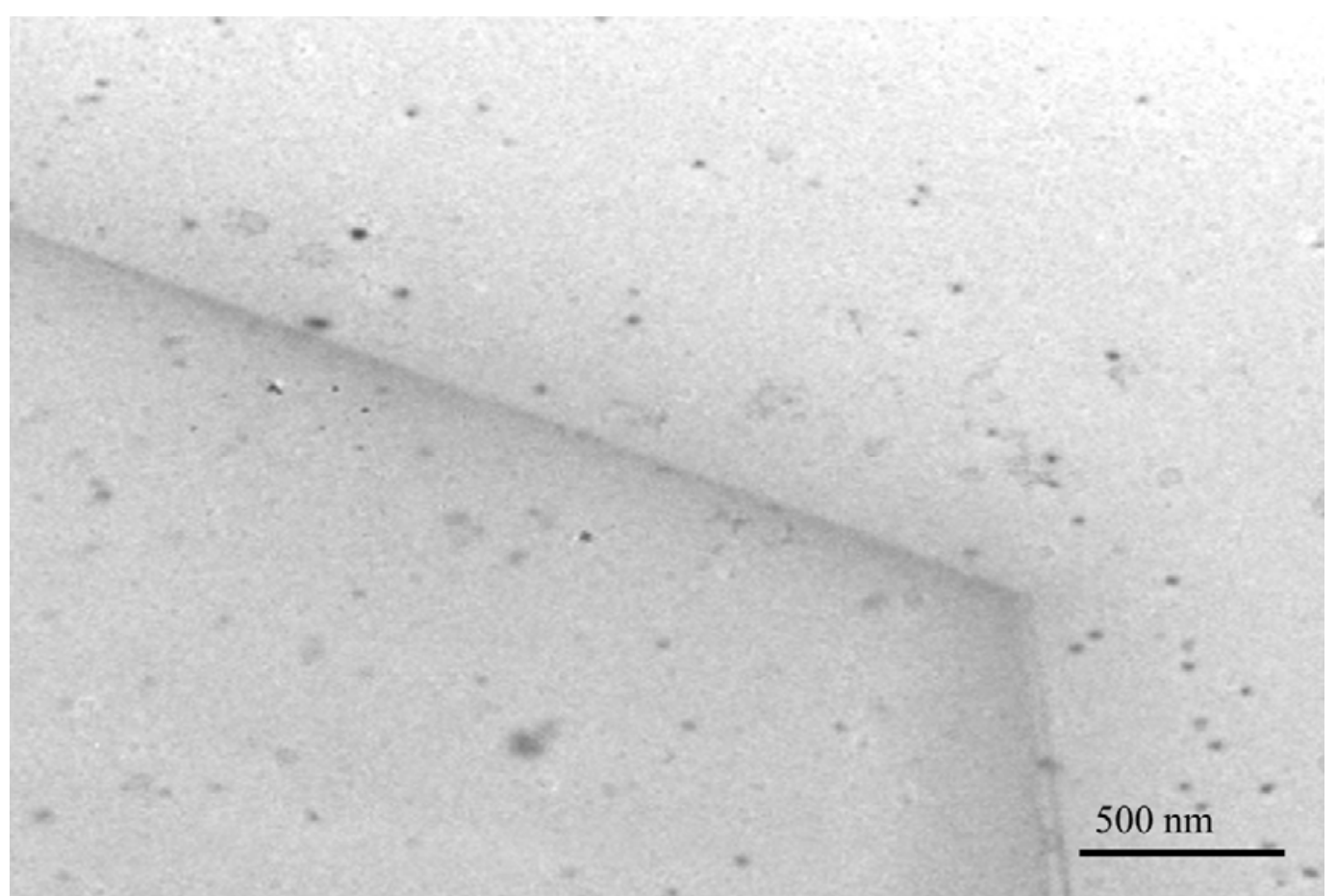

Figure 1. In-situ TEM image of the hexagonal phase of ice during crystallization surrounded by $30 \mathrm{~nm}$ Au particles. 